\title{
ANALISIS PEMASARAN PADI SAWAH DI KECAMATAN WAWOTOBI KABUPATEN KONAWE
}

\section{RICE FIELD MARKETING ANALYSIS IN WAWOTOBI SUB DISTRICT KONAWE DISTRICT}

\section{Leni Saleh}

Program Studi Agribisnis dan Agroindustri Fakultas Pertanian Universitas Lakidende Jalan Sultan Hasanuddin, No. 234, Wawotobi, Lalosabila, Unaaha, Kabupaten Konawe, Sulawesi Tenggara 93461, Indonesia lenisalehraslin@gmail.com

\begin{abstract}
ABSTRAK
Tujuan dari penelitian yaitu untuk menganalisis saluran pemasaran gabah kering panen di Kelurahan Kulahi Kecamatan Wawotobi dan untuk menganalisis margin, keuntungan dan efisiensi pemasaran gabah kering panen di Kelurahan Kulahi Kecamatan Wawotobi. Penelitian dilaksanakan di Kelurahan Kulahi Kecamatan Wawotobi Kabupaten Konawe. Populasi dalam penelitian ini adalah semua petani padi sawah yang berjumlah 20 orang dan pedagang yang pemasaran gabah sebanyak 4 orang, penentuan sampel petani padi sawah dilakukan secara sensus. Pemasaran gabah terdapat satu jenis saluran pemasaran yaitu Produsen (Petani Padi) ke Pedagang Pengumpul Desa ke Penggilingan Padi, memiliki biaya pemasaran sebesar Rp 120/ Kg. Keuntungan pemasaran pedagang pengumpul desa sebesar $\mathrm{Rp}$ 280/Kg, dan memiliki marjin pemasaran sebesar Rp 400/Kg dan keuntungan pemasaran gabah yang sudah berbentuk beras yang dilakukan oleh penggilingan padi sebesar Rp 450.000/50Kg, dan memiliki marjin pemasaran sebesar Rp 90.000/Kg. Efisiensi pemasaran gabah mencapai $89 \%$. Artinya besarnya persentase bagian harga yang diterima petani dan rendahnya biaya pemasaran yang terjadi pada lembaga pemasaran gabah di Kelurahan Kulahi Kecamatan Wawotobi Kabupaten Konawe.
\end{abstract}

Kata Kunci : Pemasaran, Padi Sawah.

\section{ABSTRACT}

The purpose of this research is to analyze the marketing channels of harvested dry unhulled rice in Kulahi Village, Wawotobi District and to analyze the margins, profits and marketing efficiency of harvested dry grain in Kulahi Village, Wawotobi District. The research was conducted in Kulahi Village, Wawotobi District, Konawe Regency. The population in this study were all lowland rice farmers, amounting to 20 people and traders who marketed grain as many as 4 people. The sample determination of lowland rice farmers was carried out by census. There is one type of marketing channel for unhulled rice, namely Producers (Rice Farmers) to Village Collecting Traders to Rice Mills, having a marketing cost of IDR 120 / Kg. The marketing profit of the village collector traders is Rp. $280 / \mathrm{Kg}$, and has a marketing margin of Rp. $400 / \mathrm{Kg}$ and the marketing profit of unhulled rice in the form of rice carried out by the rice mill is Rp. 450,000/ $50 \mathrm{~kg}$, and has a marketing margin of Rp. 90,000 / kg. Grain marketing efficiency reaches 89\%. This means that the large percentage of the price received by farmers and the low marketing costs that occur in grain marketing institutions in Kulahi Village, Wawotobi District, Konawe Regency. 


\section{Pendahuluan}

\begin{abstract}
Sektor pertanian mendapat prioritas utama dalam upaya pembangunan ekonomi karena sektor ini merupakan sektor dominan di Indonesia, baik dari kontribusi pada pendapatan nasional, penyediaan lapangan kerja, sumber devisa dan sebagainya. Jadi pembangunan pertanian mempunyai kontribusi yang besar pada pembangunan ekonomi melalui kontribusi produksi bahan makanan dan bahan mentah, kontribusi pasaran hasil dari sektor pertanian, kontribusi faktor produksi tenaga kerja dan
\end{abstract} modal (Widodo, 2008).

Keberhasilan sektor pertanian sangat tergantung pada posisi sumber daya alam yang sebagian besar terdapat di pedesaan berupa lahan pertanian, sumber air, hutan, dan tenaga kerja. Kurang lebih 80\% penduduk berdiam di pedesaan, dan sekitar 49\% dari angkatan kerja yang bekerja disektor pertanian. Namun tingkat hidup masyarakat pedesaan relatif masih rendah bila dibandingkan dengan penduduk perkotaan. Pengeluaran (pendapatan ratarata) penduduk pedesaan (petani) hanya $70 \%$ dari pengeluaran penduduk kota, bahkan ada yang di bawah setengah dari pendapatan penduduk kota $30 \%$. Jika dilihat dari aspek rasa keadilan sosial, maka pembangunan yang bertujuan meningkatkan kesejahteraan, penduduk desa perlu mendapat prioritas dan perhatian yang tinggi (Aris Saputro, 2004).

Perkembangan pembangunan pertanian khususnya tanaman padi sawah di Sulawesi Tenggara dewasa ini semakin maju sehingga tanaman padi sawah merupakan salah satu komoditi tanaman pangan yang tetap mendapat prioritas dalam pembangunan. Hal ini disebabkan selain karena beras merupakan makanan pokok sebagian besar penduduk juga karena usahatani padi sawah merupakan sumber pendapatan petani di pedesaan. Keberhasilan pembangunan pertanian tanaman padi sawah ini merupakan keberhasilan pemerintah dan instansi- instansi terkait selaku pengambil kebijakan dan strategi pembangunan pertanian tanaman padi sawah dan petani selaku pengelola usahatani padi sawah. Untuk mencapai hal tersebut, penyuluhan pertanian berperan dalam meningkatkan pengetahuan, keterampilan serta sikap petani sebagai sasaran penyuluhan pertanian agar lebih responsif terhadap hal-hal baru dan termotivasi untuk selalu berusaha lebih meningkatkan usahanya (Dinas Pertanian Provinsi Sulawesi Tenggara, 2016).

Padi sebagai komoditas pangan utama mempunyai nilai strategis yang sangat tinggi, sehingga diperlukan adanya penanganan yang serius dalam upaya peningkatan produktivitasnya. Besarnya peranan pemerintah dalam pengelolaan komoditas pangan khususnya padi dapat dil ihat mulai dari kegiatan pra produksi seperti penyediaan bibit unggul, pupuk, obat obatan, sarana irigasi, kredit produksi dan penguatan modal kelembagaan petani. Usaha peningkatan produksi dan pendapatan usahatani padi tidak akan berhasil tanpa penggunaan teknologi baru baik dibidang teknis budidaya, benih, obatobatan dan pemupukan (Ilham 2010).

Kabupaten Konawe merupakan salah satu daerah yang memiliki potensi komoditi pertanian untuk dikembangkan, khususnya tanaman padi sawah yang tumbuh subur di seluruh wilayah Konawe khususnya di Kecamatan Wawotobi sebagai wilayah sentral produksi padi sawah. Potensi dan kekayaan alam tersebut bila dimanfaatkan dengan benar dan sungguh akan menciptakan keuntungan ekonomi yang akan berdampak pada pendapatan daerah, petani, perusahaan dan masyarakat dalam rangka menciptakan lapangan kerja, meningkatkan kesejahteraan dan mengurangi pengangguran. Pemanfaatan potensi merupakan suatu strategi pembangunan yang tepat, untuk menjawab tantangan dalam rangka mewujudkan dan mengembangkan pertanian di sektor 
tanaman pangan, khususnya budidaya padi sawah, dalam rangka menciptakan produk yang bernilai ekonomis tinggi. Dalam rangka menciptakan produk yang bernilai ekonomis maka keseimbangan antara industri dan tanaman pangan baik dari segi pendapatan usahatani, maupun lembagalembaga yang terlibat dalam pemasaran produk dalam rangka mensukseskan otonomi daerah sangat dibutuhkan.

Berdasarkan hal tersebut, maka tujuan dari penelitian yaitu untuk menganalisis saluran pemasaran gabah kering panen di Kelurahan Kulahi Kecamatan Wawotobi dan untuk menganalisis margin, keuntungan dan efisiensi pemasaran gabah kering panen di Kelurahan Kulahi Kecamatan Wawotobi.

\section{Metode Penelitian}

\section{Tempat dan Waktu Penelitian}

Penelitian dilaksanakan di

Kelurahan Kulahi Kecamatan Wawotobi Kabupaten Konawe. Penentuan lokasi penelitian dilakukan secara sengaja (purposive) dengan pertimbangan bahwa daerah tersebut salah satu daerah sentra produksi padi sawah yang potensial di Kabupaten Konawe.

\section{Populasi dan Sampel}

Populasi dalam penelitian ini adalah semua petani padi sawah yang berjumlah 20 orang dan pedagang yang pemasaran gabah sebanyak 4 orang, penentuan sampel petani padi sawah dilakukan secara sensus.

\section{Jenis dan Sumber Data}

Jenis data yang dikumpulkan untuk mencapai tujuan penelitian ini adalah data primer dan data sekunder yaitu :

1. Data primer, dengan melakukan wawancara secara langsung dengan responden berdasarkan daftar pernyataan (kuisioner).

2. Data sekunder, diperoleh dari instansi seperti BPS, Dinas Pertanian dan Tanaman pangan serta Instansi lain yang terkait dengan penelitian ini.

\section{Variabel Yang Diamati}

Variabel yang diamati dalam penelitian ini adalah sebagai berikut :
1. Identitas responden, yang meliputi : umur, pendidikan, jumlah anggota keluarga, dan pengalaman dalam berusaha.

2. Karakteristik pemasaran padi sawah (gabah) yang meliputi : lembaga pemasaran, harga penjualan dan pembelian lembaga pemasaran, biaya penjualan dan pembelian lembaga pemasaran, harga jual petani, harga eceran, dan perubahan harga ditingkat petani atau konsumen.

\section{Analisis Data}

Berdasarkan tujuan penelitian maka dilakukan analisa sebagai berikut :

1. Untuk melihat saluran pemasaran dan peran masing-masing lembaga pemasaran, dianalisa secara deskriptif.

2. Margin, keuntungan dan efisiensi pemasaran gabah di Kelurahan Kulahi Kecamatan Wawotobi dianalisis sebagai berikut :

a. Margin Pemasaran :

Keterangan

$$
\mathrm{M}=\mathrm{He}-\mathrm{Hp}
$$

M : Marjin Pemasaran Gabah

$$
\left(\mathrm{Rp} \mathrm{Kg}^{-1}\right)
$$

$\mathrm{He}$ : Harga Gabah pada tingkat pedagang $\left(\mathrm{Rp} \mathrm{Kg}^{-1}\right)$

Hp : Harga Gabah pada tingkat petani $\left(\mathrm{Rp} \mathrm{Kg}^{-1}\right)$

b. Keuntungan Pelaku Pemasaran :

$\mathrm{M}=\mathrm{B}+\pi$ atau $\quad \pi=\mathrm{M}-\mathrm{B}$

Keterangan :

B : Biaya Pemasaran Gabah

$\pi$ : Besarnya keuntungan yang diperoleh pelaku pemasaran.

M : Marjin Pemasaran Gabah

c. Efisiensi Pemasaran :

$$
\mathrm{EP}=1-\frac{\mathrm{M}}{\mathrm{He}} \times 100 \%
$$

Keterangan :

EP : Persentase harga yang diterima

M : Marjin Pemasaran Gabah

$\mathrm{He}$ : Harga Gabah pada tingkat pedagang $\left(\mathrm{Rp} \mathrm{Kg}^{-1}\right)$

Dengan Kriteria 
- $\quad$ Bila EP < 50\% berarti saluran pemasaran belum efisien

- Bila EP > 50\% berarti saluran pemasaran sudah efisien

\section{Hasil dan Pembahasan}

\section{Gambaran Umum Daerah Penelitian}

Kelurahan Kulahi merupakan salah satu bagian dari wilayah Kecamatan Wawotobi Kabupaten Konawe. Jarak Kelurahan Kulahi dari ibukota kecamatan $\pm 2 \mathrm{Km}$ dan jarak dari ibukota kabupaten \pm $8 \mathrm{Km}$. Secara administratif Kelurahan Kulahi mempunyai batasan-batasan wilayah sebagai berikut :

a. Sebelah Utara berbatasan dengan Konawe Utara

b. Sebelah Selatan berbatasan dengan Desa Larowiu

c. Sebelah Barat berbatasan dengan Desa Ahuhu

d. Sebelah Timur berbatasan dengan Desa Lamelay

Luas wilayah daratan Kelurahan

Kulahi sekitar $8.868 \mathrm{Ha}$ atau 17,48 persen dari luas wilayah daratan Kecamatan Wawotobi. Permukaan tanah pada umumnya bergunung dan berbukit yang diapit dataran rendah yang sangat potensial untuk pengembangan sector pertanian, peternakan, perikanan, dan perkebunan (BPS Konawe, 2019)

Iklim Kelurahan Kulahi pada dasarnya sama dengan iklim di daerahdaerah lain di Indonesia, yakni iklim tropis tipe C3 dengan dua musim yaitu 6 bulan basah dan 6 bulan kering. Kelurahan Kulahi mempunyai potensi yang dapat dikembangkan yaitu 5 sub sektor yaitu perkebunan, hortikultura, peternakan, kehutanan, dan perikanan. Tingkat kemasaman tanah $(\mathrm{pH})$ antara $4-6$.

Mata pencaharian penduduk Kelurahan Kulahi Kecamatan Wawotobi sebagian besar adalah sebagai petani. Sedangkan selebihnya berprofesi sebagai pengusaha dan Pegawai Negeri. Petani di Kelurahan Kulahi mengusahakan berbagai jenis tanaman hortikultura diantaranya padi sawah dan jagung.

\section{Identitas Responden \\ Petani Padi Sawah}

1. Umur Petani

Faktor yang dapat mempengaruhi kemampuan fisik dalam bekerja dan berfikir adalah umur seseorang, selain itu umur juga dapat mempengaruhi tingkat keterampilan dalam mengelola usahataninya. Kemampuan yang lebih besar terdapat pada umur muda karena pada umur tersebut biasanya yang lebih berani mengambil resiko, sehingga lebih dinamis dibanding dengan umur tua yang cenderung bersikap berhati-hati dalam mengambil keputusan.

Tabel 1. Keadaan Umur Responden Petani Padi Sawah di Kelurahan Kulahi Kecamatan Wawotobi (Data Hasil Penelitian diolah 2019)

\begin{tabular}{cccc}
\hline No & $\begin{array}{c}\text { Tingkat } \\
\text { Umur } \\
\text { (Tahun) }\end{array}$ & $\begin{array}{c}\text { Jumlah } \\
\text { (jiwa) }\end{array}$ & $\begin{array}{c}\text { Persentase } \\
(\boldsymbol{\%})\end{array}$ \\
\hline 1 & $22-54$ & 20 & 100 \\
2 & $>54$ & - & - \\
\hline & Jumlah & $\mathbf{2 0}$ & $\mathbf{1 0 0}$ \\
\hline
\end{tabular}

Berdasarkan tabel 1 menunjukkan bahwa petani padi sawah di wilayah penelitian cukup memberikan harapan karena sebagian besar atau $100 \%$ petani responden berada pada kisaran umur yang produktif yang diharapkan dapat lebih mampu melihat perkembangan pasar dari komoditi padi sawah (padi sawah) yang diusahakan sehingga dapat memperoleh keuntungan yang maksimal.

2. Tingkat Pendidikan Petani

Faktor lain yang juga mendasari dalam menerapkan suatu teknologi adalah tingkat pendidikan. Tingkat pendidikan dapat mempengaruhi perilaku petani dalam menyerap informasi terutama yang berkaitan dengan usahataninya. Pendidikan yang tinggi dengan umur yang relatif masih muda akan menyebabkan petani lebih dinamis, berfikir lebih baik dan diharapkan dapat lebih mudah menerima dan menerapkan inovasi baru. Keadaan tingkat pendidikan petani responden dapat dilihat pada Tabel 2. 
Tabel 2 . Keadaan Tingkat Pendidikan Responden Petani Padi Sawah di Kelurahan Kulahi (Data Hasil Penelitian diolah 2019)

\begin{tabular}{clcc}
\hline No & $\begin{array}{c}\text { Tingkat } \\
\text { Pendidikan }\end{array}$ & $\begin{array}{c}\text { Jumlah } \\
\text { (jiwa) }\end{array}$ & $\begin{array}{c}\text { Persentase } \\
(\boldsymbol{\%})\end{array}$ \\
\hline 1 & SD & 7 & 35 \\
2 & SMP & 1 & 5 \\
3 & SMA & 12 & 60 \\
\hline & Jumlah & $\mathbf{2 0}$ & $\mathbf{1 0 0}$ \\
\hline
\end{tabular}

Berdasarkan data pada tabel 2 menunjukkan bahwa seluruh petani responden pernah mengalami jenjang pendidikan formal dengan persentase tertinggi ada pada pendidikan SMA yaitu $60 \%$. Tingkat pendidikan yang dimiliki petani diharapkan mampu mengolah dan memanfaatkan informasi dan sumberdaya yang dimiliki dalam meningkatkan usahataninya, dapat berpikir dengan baik sehingga berani mengambil keputusan dalam menentukan kegiatan pemasaran yang lebih efisien terutama tentang pemilihan saluran pemasaran yang menguntung sebab banyak ditemukan ditingkat petani bahwa pemilihan saluran yang menguntung bukan menjadi prioritas petani tetapi bagaimana produk cepat menghasilkan uang.

3. Jumlah Tanggungan Keluarga

Jumlah tanggungan keluarga merupakan sumber daya manusia yang dapat dimanfaatkan sebagai tenaga kerja yang potencial. Selain itu dapat pula berperan sebagai tenaga kerja yang potensial dan sebagai mitra diskusi untuk mempertimbangkan dan menyikapi suatu teknologi baru. Petani sebagai kepala keluarga senantiasa berupaya untuk memenuhi kebutuhan keluarganya, karena itu semakin besar tanggungan keluarga akan semakin kuat pula usahanya dalam memenuhi kebutuhan hidup keluarganya. Hal ini yang senantiasa mendorong petani untuk meningkatkan produksi padi sawahnya semaksimal mungkin. Menurut Soeharjo dan Patong (1999) bahwa yang termasuk tanggungan keluarga kecil yaitu berkisar $1-4$ orang sedangkan tanggungan kelurga $\geq 5$ orang termasuk keluarga besar. Keadaan jumlah tanggungan keluarganya petani responden diKelurahan Kulahi dapat dilihat pada Tabel 3.

Tabel 3 . Keadaan Jumlah Tanggungan Responden Petani Padi Sawah di Kelurahan Kulahi (Data Hasil Penelitian diolah 2019)

\begin{tabular}{cccc}
\hline No & $\begin{array}{c}\text { Jumlah } \\
\text { Tanggungan }\end{array}$ & $\begin{array}{c}\text { Jumlah } \\
\text { (jiwa) }\end{array}$ & $\begin{array}{c}\text { Persenta } \\
\text { se }(\%)\end{array}$ \\
\hline 1 & $1-5$ (Kecil) & 20 & 100 \\
2 & $\geq 5$ (Besar) & - & - \\
\hline & Jumlah & $\mathbf{2 0}$ & $\mathbf{1 0 0}$ \\
\hline
\end{tabular}

Berdasarkan data pada Tabel 3 menunjukkan bahwa rata-rata responden memiliki tanggungan keluarga yang relatif kecil (1- 5 orang) yaitu sekitar 100\% yang memungkinkan untuk senantiasa berusaha meningkatkan pendapatannya dan kegiatan pemasaran dapat didukung oleh tenaga kerja keluarga yang dimilikinya.

4. Pengalaman Berusahatani Padi sawah

Pengalaman berusahatani memiliki peranan yang sangat penting bagi seseorang petani dalam menerapkan teknologi baru. Pengalaman merupakan guru yang paling bijak yang memiliki arti penting bagi petani, karena pengalaman, baik yang dialami sendiri, dilihat dan didengar dari sesama petani, petugas maupun media massa dapat dijadikan pedoman atau petunjuk untuk memiliki alternatif yang lebih baik dan mengelola usahatani. Menurut Soeharjo dan Patong (1999) bahwa dikatakan cukup pengalaman apabila telah menggeluti pekerjaan berusahatani selama $5-10$ tahun, sedangkan kategori sangat pengalaman jika telah menggeluti selama lebih dari 10 tahun, serta kategori kurang pengalaman jika baru menggeluti pekerjaan berusahatani selama 5 tahun. Keadaan pengalaman berusahatani petani responden dapat dilihat pada Tabel 4 . 
Tabel 4. Keadaan Pengalaman Berusahatani Petani Padi Sawah Di Kelurahan Kulahi (Data Hasil Penelitian diolah 2019)

\begin{tabular}{cccc}
\hline No & $\begin{array}{c}\text { Lama } \\
\text { Pengalaman } \\
\text { (Tahun) }\end{array}$ & $\begin{array}{c}\text { Jumlah } \\
\text { (jiwa) }\end{array}$ & $\begin{array}{c}\text { Persenta } \\
\text { se }(\boldsymbol{\%})\end{array}$ \\
\hline 1 & $<5$ & 1 & 5 \\
2 & $5-10$ & 16 & 80 \\
3 & $>10$ & 3 & 15 \\
\hline & Jumlah & $\mathbf{2 0}$ & $\mathbf{1 0 0}$ \\
\hline
\end{tabular}

Berdasarkan data pada Tabel 4 menunjukkan bahwa $80 \%$ petani memiliki cukup pengalaman dalam berusahatani padi sawah sehingga dengan pengalaman tersebut diharapkan dapat menjadi motivasi untuk mengembangkan usahatani padi sawah dan kegiatan pemasaran padi sawah yang lebih efisien dengan saluran pemasaran yang tepat.

\section{Pedagang Pengumpul Desa}

1. Umur

Umur dapat mempengaruhi kemampuan seseorang dalam berdagang terutama berkaitan dengan fisik dan fikir. Pada umumnya yang sehat dan beumur muda akan lebih agresif dalam melaksanakan kegiatan perdagangan. Umur pedagang yang menjadi responden dalam penelitian ini dapat dilihat tabel 5 .

Tabel 5. Keadaan Umur Pedagang Padi Sawah (Gabah Kering Panen) di Kelurahan Kulahi (Data Hasil Penelitian diolah 2019)

\begin{tabular}{cccc}
\hline No & $\begin{array}{c}\text { Tingkat } \\
\text { Umur } \\
\text { (Tahun) }\end{array}$ & $\begin{array}{c}\text { Jumlah } \\
\text { (jiwa) }\end{array}$ & $\begin{array}{c}\text { Persentase } \\
(\boldsymbol{\%})\end{array}$ \\
\hline 1 & $22-54$ & 4 & 100 \\
2 & $>54$ & - & - \\
\hline & Jumlah & $\mathbf{4}$ & $\mathbf{1 0 0}$ \\
\hline
\end{tabular}

Berdasarkan data pada tabel 5 memperlihatkan bahwa pedagang yang menjadi responden dalam penelitian ini memiliki umur produktif dan ini merupakan modal yang cukup mendukung dalam pengembangan usahanya.
2. Pendidikan

Tingkat pendidikan dapat mempengaruhi perilaku pedagang dalam menyerap informasi terutama yang berkaitan dengan usahanya. Pendidikan yang tinggi dengan umur yang relatif masih muda akan menyebabkan pedagang akan dinamis, berfikir lebih baik dan diharapkan dapat lebih mudah menerima dan menerapkan inovasi baru. Tingkat pendidikan pedagang pengumpul desa dapat dilihat pada tabel 6 .

Tabel 6. Keadaan Tingkat Pendidikan Pedagang Pengumpul Desa di Kelurahan Kulahi (Data Hasil Penelitian diolah 2019)

\begin{tabular}{clcc}
\hline No & $\begin{array}{c}\text { Tingkat } \\
\text { Pendidikan }\end{array}$ & $\begin{array}{c}\text { Jumlah } \\
\text { (jiwa) }\end{array}$ & $\begin{array}{c}\text { Persentase } \\
(\%)\end{array}$ \\
\hline 1 & SD & - & - \\
2 & SMP & - & - \\
3 & SMA & 4 & 100 \\
\hline & Jumlah & $\mathbf{4}$ & $\mathbf{1 0 0}$ \\
\hline
\end{tabular}

Berdasarkan data pada tabel 6 menunjukkan bahwa tingkat pendidikan pedagang pengeumpul desa cukup baik yaitu $100 \%$ mempunyai pendidikan SMA. Kondisi ini merupakan keunggulan yang dimiliki oleh pedagang pengumpul desa sehingga pendidikan yang cukup dapat berdampak pada peningkatan kegiatan pemasaran.

3. Jumlah Tanggungan keluarga

Untuk melihat jumlah tanggungan keluarga pedagang pengumpul desa dapat dilihat pada tabel 7 berikut.

Tabel 7. Keadaan Jumlah Tanggungan

Pedagang Pengumpul Desa di

Kelurahan (Data Hasil Penelitian diolah 2019)

\begin{tabular}{cccc}
\hline No & $\begin{array}{c}\text { Jumlah } \\
\text { Tanggungan }\end{array}$ & $\begin{array}{c}\text { Jumlah } \\
\text { (jiwa) }\end{array}$ & $\begin{array}{c}\text { Persenta } \\
\text { se }(\boldsymbol{\%})\end{array}$ \\
\hline 1 & $1-5($ Kecil) & 4 & 100 \\
2 & $\geq 5$ (Besar) & - & - \\
\hline & Jumlah & $\mathbf{4}$ & $\mathbf{1 0 0}$ \\
\hline
\end{tabular}

Berdasarkan data pada tabel 7 menunjukkan bahwa rata-rata responden pedagang memiliki tanggungan keluarga kecil yaitu $100 \%$ kondisi ini dapat 
memberikan motivasi untuk bekerja lebih giat dan berusaha memenuhi kebutuhan keluarganya dengan mengembangkan usahanya kearah yang lebih maju.

4. Pengalaman Pemasaran padi sawah

Pengalaman pemasaran merupakan salah satu faktor yang dapat mempengaruhi kemampuan seseorang dalam menjalankan usahanya. Pedagang pengumpul desa yang menjadi responden dalam penelitian ini dapat dilihat pada tabel 8.

Tabel 8. Keadaan Pengalaman Berusaha Pedagang Pengumpul Desa di Kelurahan Kulahi (Data Hasil Penelitian diolah 2019)

\begin{tabular}{cccc}
\hline No & $\begin{array}{c}\text { Lama } \\
\text { Berusaha } \\
\text { (Tahun) }\end{array}$ & $\begin{array}{c}\text { Jumlah } \\
\text { (jiwa) }\end{array}$ & $\begin{array}{c}\text { Persentase } \\
(\%)\end{array}$ \\
\hline 1 & $<5$ & - & - \\
2 & $5-10$ & 4 & 100 \\
3 & $>10$ & - & - \\
\hline & Jumlah & $\mathbf{4}$ & $\mathbf{1 0 0}$ \\
\hline
\end{tabular}

Berdasarkan data pada tabel 8 menunjukkan bahwa pedagang yang menjadi responden dalam penelitian ini memiliki pengalaman berusaha yang cukup yaitu 4 orang (100\%). Hal ini menunjukkan bahwa pedagang yang melakukan kegiatan pemasaran padi sawah di Kelurahan Kulahi sudak cukup berpengalam sehinga ini dapat menajdi modal sosial yang dapat dimanfaatkan untuk mengembangkan usahanya agar lebih maju.

\section{Analisis Pemasaran}

\section{Saluran Pemasaran}

Pada penelitian pemasaran padi sawah di Kelurahan Kulahi Kecamatan Wawotobi Kabupaten Konawe didapatkan bahwa dalam melakukan pemasaran padi sawah hanya terdapat satu saluran pemasaran. Saluran pemasaran tersebut secara lengkap dapat dilihat pada bagan di bawah ini :

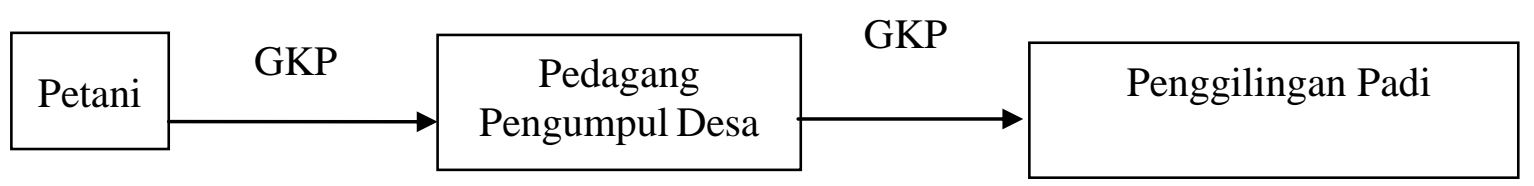

Gambar 1. Saluran pemasaran padi sawah dalam wilayah pembelian di Kelurahan Kulahi Kecamatan Wawotobi Tahun 2019

- Saluran Pemasaran I : Petani Produsen

Keterangan :

GKP = Gabah Kering Panen

PPD = Pedagang Pengumpul Desa

Saluran pemasaran padi sawah hanya dua saluran pemasaran dengan melibatkan satu lembaga pemasaran yaitu Pedagang Pengumpul Desa. Petani tidak memasarkan padi sawah secara langsung kepada konsumen (penggilingan padi), hal ini disebabkan besarnya biaya yang harus dikeluarkan petani jika harus menjual langsung kepenggilingan padi karena lokasi penggilingan cukup jauh.
PPD $\longrightarrow$ Penggilingan Padi

\section{Marjin, Biaya, dan Keuntungan Pemasaran}

Marjin adalah selisih antara harga penjualan dan harga pembelian yang terjadi selama proses pemasaran. Margin dan keuntungan yang diperoleh lembaga pemasaran yang menyalurkan biji padi (padi sawah) di Kelurahan Kulahi dapat dilihat pada Tabel 9 berikut. 
Tabel 9. Marjin, Biaya, dan Keuntungan Pemasaran Padi sawah di Kelurahan Kulahi (Hasil Olahan Data Primer 2019)

\begin{tabular}{llccccc}
\hline No & $\begin{array}{c}\text { Lembaga } \\
\text { Pemasaran }\end{array}$ & $\begin{array}{c}\text { Harga Beli } \\
(\mathbf{R p} / \mathbf{K g})\end{array}$ & $\begin{array}{c}\text { Harga } \\
\text { Jual } \\
(\mathbf{R p} / \mathbf{K g})\end{array}$ & $\begin{array}{c}\text { Marjin } \\
(\mathbf{R p} / \mathbf{K g})\end{array}$ & $\begin{array}{c}\text { Biaya } \\
(\mathbf{R p} / \mathbf{K g})\end{array}$ & $\begin{array}{c}\text { Keuntungan } \\
(\mathbf{R p} / \mathbf{K g})\end{array}$ \\
\hline I & $\begin{array}{l}\text { Pedagang } \\
\text { Pengumpul } \\
\text { Desa }\end{array}$ & 3.200 & 3.600 & 400 & 120 & 280 \\
\hline II & $\begin{array}{l}\text { Penggilinga } \\
\text { n Padi (PP) }\end{array}$ & $\begin{array}{c}3.600 / \mathrm{Kg} \\
360.000 / \\
100 \mathrm{Kg}\end{array}$ & 450.000 & 90.000 & 30.500 & 59.500 \\
& & & & & \\
\hline
\end{tabular}

Tabel 9 menunjukkan bahwa harga beli terendah adalah di Pedagang Pengumpul Desa yaitu Rp.3.200/Kg dan tertinggi pada Penggilingan Padi yaitu Rp.3.600/Kg,-. Harga jual terendah pada Pedagang Pengumpul Desa yaitu Rp.3.600,-/Kg dan tertinggi pada Penggilingan Padi yaitu Rp.450.000,$150 \mathrm{Kg}$ sudah berbentuk beras. Berdasarkan penjelasan pedagang desa bahwa harga jual ketingkat PPD ditentukan berdasarkan besarnya biaya pemasaran dan keuntungan yang dinginkan oleh pedagang itu sendiri, hal ini berbeda dengan penentuan harga ditingkat PP pada komoditas lainnnya. Hal lain yang menarik dari kegiatan pemasaran padi sawah khususnya yang terjadi di Kelurahan Kulahi Kecamatan Wawotobi adalah biaya pemasaran ditanggung bersama antara pedagang pengumpul desa dengan pemilik penggilingan padi yaitu untuk biaya pemasaran tenaga kerja ditanggung oleh pedagang pengumpul desa sedang biaya lainnya seperti angkutan, pengemasan, penyimpanan, bongkar muat, dan retribusi ditanggung oleh pemilik penggilingan padi.

\section{Efisiensi Pemasaran Padi Sawah}

Efisiensi pemasaran dapat diukur dengan menghitung bagian harga yang diterima petani responden dengan ketentuan bahwa jika bagian harga yang diterima petani responden lebih dari $50 \%$ dikatakan pemasaran efisien. Adapun efisiensi pemasaran padi sawah di Kelurahan Kulahi dapat dilihat pada tabel 10 berikut.

Tabel 10. Efisiensi pemasaran padi sawah di Kelurahan Kulahi (Hasil Olahan Data Primer 2019)

\begin{tabular}{lccccc}
\hline No & $\begin{array}{c}\text { Harga } \\
\text { yang } \\
\text { diterima } \\
\text { Produsen } \\
(\mathbf{R p} / \mathbf{K g})\end{array}$ & $\begin{array}{c}\text { Margin } \\
\text { Pemasaran } \\
(\mathbf{R p} / \mathbf{K g})\end{array}$ & $\begin{array}{c}\text { Harga yang } \\
\text { dibayarkan } \\
\text { Pedagang } \\
(\mathbf{R p} / \mathbf{K g})\end{array}$ & $\begin{array}{c}\text { Bagian harga } \\
\text { yang diterima } \\
\text { Petani (Efisiensi } \\
\text { Pemasaran) } \\
(\%)\end{array}$ & Keterangan \\
\hline 1 & 3.200 & 400 & 3.600 & 89 & Efisien \\
\hline 2 & 3.600 & 90.000 & $\begin{array}{c}450.000 / 50 \mathrm{Kg} \\
\text { beras }\end{array}$ & 80 & Efisien \\
\hline
\end{tabular}

Berdasarkan data pada tabel 10 memperlihatkan bahwa efisiensi yang diperoleh oleh lembaga pemasaran pedagang pengumpul desa sebesar $89 \%$. Angka 89\% ini besarnya persentase bagian harga yang diterima petani dan rendahnya 
biaya pemasaran yang terjadi pada lembaga pemasaran padi sawah di Kelurahan Kulahi Kecamatan Wawotobi Kabupaten Konawe.

\section{Kesimpulan dan Saran \\ Kesimpulan}

1. Pemasaran gabah terdapat satu jenis saluran pemasaran yaitu Produsen (Petani Padi) ke Pedagang Pengumpul Desa ke Penggilingan Padi, memiliki biaya pemasaran sebesar Rp 120/ Kg. Keuntungan pemasaran pedagang pengumpul desa sebesar $\mathrm{Rp} 280 / \mathrm{Kg}$, dan memiliki marjin pemasaran sebesar Rp 400/Kg dan keuntungan pemasaran gabah yang sudah berbentuk beras yang dilakukan oleh penggilingan padi sebesar Rp $450.000 / 50 \mathrm{Kg}$, dan memiliki marjin pemasaran sebesar Rp 90.000/Kg.

2. Efisiensi pemasaran gabah mencapai 89\%. Artinya besarnya persentase bagian harga yang diterima petani dan rendahnya biaya pemasaran yang terjadi pada lembaga pemasaran gabah di Kelurahan Kulahi Kecamatan Wawotobi Kabupaten Konawe.

\section{Saran}

Pada kegiatan pemasaran gabah, petani hanya dapat menerima harga yang ditawarkan oleh para pedagang dengan harga yang berbeda-beda. Untuk mendapatkan harga yang lebih tinggi seharusnya petani lebih aktif dalam mencari informasi harga di pasar.

\section{Daftar Pustaka}

Aris, S. 2004. Perkembangan Pembangunan pertanian Pedesaan di Indonesia, Raja Grafindo Persada.

Biro Pusat Statistik. 2019. Sensus Pertanian Sulawesi Tenggara.

Biro Pusat Statistik. 2016. Dinas Pertanian Sulawesi Tenggara.

Biro Pusat Statistik. 2019. Kabupaten Konawe.
Nurland, F. 1986. Pemasaran Produksi Pertanian. LEPHAS. Ujung Pandang.

Rasyad, M. 2008. Memasarkan Hasil Pertanian dan Peternakan. Penebar Swadaya. Jakarta.

Soehardjo, dan Patong, D. 1999. Sendisendi Pokok Ilmu Usaha Tani. Departemen Ilmu Ilmu Sosial. Institute Pertanian Bogor.

Widodo, S. 2008. Campur sari Agro Ekonomi, Liberty Yogyakarta. 